\title{
Lymphocyte vaccination protects prediabetic non-obese diabetic mice from developing diabetes mellitus
}

\author{
C.L. Gearon, M.J. Hussain, D. Vergani, M. Peakman \\ Department of Immunology, King's College School of Medicine and Dentistry, London, UK
}

\begin{abstract}
Summary In the therapeutic manoeuvre termed "lymphocyte vaccination", activated lymphocytes capable of transferring an autoimmune disease are instead attenuated and given in vaccine form. We have previously shown that such a therapy administered to non-obese diabetic (NOD) mice at 6 weeks of age prevents diabetes mellitus. To assess whether this therapy has potential clinical relevance, in the present study lymphocyte vaccination was applied in NOD mice in 3 weekly doses commencing in the immediate prediabetic period (age 12 weeks), when insulitis is advanced and diabetes incipient. Of 30 NOD mice receiving active vaccine (composed of attenuated lymphocytes from diabetic NOD mice) 13 $(43.3 \%)$ remained non-diabetic to the age of 30 weeks, in comparison with 2 of $30 \quad(6.7 \%$; $p<0.01$ ) mice receiving a control vaccine (composed of attenuated lymphocytes from non-diabetic NOD/ B10 mice) and 5 of $26(19.2 \% ; p<0.01)$ mice receiving saline carrier alone. Moreover, in an additional group of 10 NOD mice receiving active vaccine weekly between 12 and 30 weeks, 8 remained diabetes free
\end{abstract}

at the end of the treatment. The most notable effect of the vaccine was that the delay in diabetes onset was accompanied by a reduction in insulitis and in some cases a complete absence of infiltrating lymphocytes at 30 weeks of age. Immunocytochemistry indicated that when present, islet infiltrating lymphocytes in non-diabetic mice that received active vaccine showed significantly reduced staining for interferon- $\gamma$, compared with the infiltrate seen in diabetic mice receiving the control vaccine or saline. This study demonstrates that the rapid progression to diabetes typically seen in 12-week-old NOD mice can be delayed by lymphocyte vaccination, supporting the possibility that a vaccine composed of attenuated autologous peripheral blood lymphocytes could be effective in high risk first degree relatives of patients with insulin dependent diabetes mellitus. [Diabetologia (1997) 40: 1388-1395]

Keywords $\mathrm{T}$ lymphocytes, lymphocyte vaccination, NOD mouse, autoimmune diabetes, immunotherapy.
Insulin-dependent diabetes mellitus (IDDM) is an autoimmune disorder in which destruction of beta

Received: 6 May 1997 and in revised form: 24 July 1997

Corresponding author: Dr. M. Peakman, Department of Immunology, King's College School of Medicine and Dentistry, Bessemer Road, London SE5 9PJ, UK

Abbreviations: NOD, Non-obese diabetic; IDDM, insulin dependent diabetes mellitus; IFN- $\gamma$, interferon- $\gamma$; IL-4, interleukin-4; Con A, concanavalin A; PBS, phosphate buffered saline; HBSS, Hank's balanced salt solution; FITC, fluorescein isothiocyanate; $\mathrm{PE}$, phycoerythrin; $\mathrm{mAbs}$, monoclonal antibodies; IL-2, interleukin-2. cells in the islets of Langerhans leads to insulin deficiency. This process is believed to be mediated by autoreactive T cells. In a close animal model of IDDM, the non-obese-diabetic (NOD) mouse, more direct evidence is available that autoreactive T lymphocytes are pathogenic, since diabetes can be transferred from diabetic mice to naïve recipients using $\mathrm{T}$ lymphocytes alone [1]. Such a mechanism of transfer has also been demonstrated in other animal models of human autoimmune disease, leading to the development of a strategy of disease prevention that exploits this pathogenicity in a manoeuvre termed "lymphocyte vaccination" [2]. 
In conventional vaccination, pathogenic agents are presented to the immune system in a safe, attenuated form, provoking an immune response in order that protection may be acquired against subsequent exposure to the pathogen. By the same principle, vaccination using attenuated, autoreactive lymphocytes has been shown to prevent disease in several animal models of autoimmunity [2-4]. More recently, small clinical trials involving patients with multiple sclerosis and rheumatoid arthritis [5-7] show that the therapy is well tolerated and has some measurable effects on autoimmune reactivity.

In a previous study to examine whether lymphocyte vaccination could be a potential treatment in human IDDM, we lymphocyte vaccinated NOD mice prophylactically from 6 weeks of age, achieving a $50 \%$ decrease in diabetes incidence [8]. Although this study was an important first step in establishing the potential of such a therapy in human IDDM, prophylactic treatment at an equivalent early age in man is unlikely to be feasible. However, screening of first degree relatives of patients with IDDM is now effective in identifying, with high sensitivity and specificity, individuals with evidence of islet autoimmunity and at high risk of developing IDDM within 5 to 10 years [9]. Since it is important to establish whether therapies such as lymphocyte vaccination could be effective in prediabetic individuals we carried out the present study, in which prediabetic NOD mice aged 12 weeks were lymphocyte vaccinated. In addition, to examine the possible effects of the therapy on cellular immune activation, the cytokines interferon- $\gamma$ (IFN- $\gamma$ ) and interleukin-2 (IL-2) and IL-4 in serum and in the islet infiltrate were assessed.

\section{Materials and methods}

Mice. The NOD mouse colony at King's College School of Medicine and Dentistry has an incidence of diabetes of approximately $95 \%$ at 30 weeks of age in both females and males. Diabetes is diagnosed using urinary glucose testing (values $>8.3 \mathrm{mmol} / \mathrm{l}$ on two occasions $72 \mathrm{~h}$ apart) and confirmed by blood glucose measurement over $16.7 \mathrm{mmol} / \mathrm{l}$. The mice were obtained originally as a breeding nucleus from Dr. M. Hattori, Joslin Diabetes Center, Boston, Mass., USA, are maintained in a clean but not specific pathogen free environment and fed ad libitum. Protective conditions include limited access, use of protective clothing, separate food stores, autoclaved drinking water and regular monitoring for infectious pathogens. Female mice from the B10-HTG strain (HarlanOlac, Bicester, UK) which is known to share the same MHC class I alleles $\left(\mathrm{K}^{\mathrm{d}}, \mathrm{D}^{\mathrm{b}}\right)$ with the NOD mouse [10] were crossed with male NOD mice and splenocytes from mice of the F1 generation from this cross (NOD/B10-HTG, which do not develop diabetes) were used to derive the control lymphocyte vaccine.

Vaccine preparation. As previously described, spleens from NOD mice demonstrating glycosuria on two separate occasions $24 \mathrm{~h}$ apart, were removed, minced and homogenised [8]. The resulting cell suspension was separated on a Lymphoprep density gradient (Nycomed UK Ltd, Birmingham, UK). The mononuclear cells were recovered, resuspended in Hank's balanced salt solution (HBSS; Life Technologies Ltd, Paisley, UK) and washed twice for $10 \mathrm{~min}$ at $200 \mathrm{~g}$. The mononuclear cells were then cultured at $2 \times 10^{6}$ cells $/ \mathrm{ml}$ in RPMI-1640 (Life Technologies Ltd) supplemented with $10 \%$ fetal calf serum (FCS; Life Technologies Ltd) and $2.5 \mu \mathrm{g} / \mathrm{ml}$ concanavalin A (Con A; Sigma Chemical Co, Poole, UK) for 3 days. Lymphocyte blasts were isolated by separation on a Lymphoprep density gradient as above, washed twice in HBSS and then attenuated by incubating $1 \times 10^{8}$ cells in $5 \mathrm{ml}$ of $0.3 \%$ gluteraldehyde (Sigma Chemical Co.) in phosphate buffered saline (PBS, $\mathrm{pH}$ 7.4) for $15 \mathrm{~min}$ at room temperature. The treated blasts were washed twice and cryopreserved in $5 \times 10^{6}$ cell aliquots in $1 \mathrm{ml}$ of $75 \%$ FCS, $11 \%$ RPMI-1640 and $14 \%$ dimethylsulphoxide (BDH, Dagenham, UK). The control vaccine was composed of identically treated splenocytes from NOD/B10-HTG F1 generation mice of similar age range to those used for the active vaccine.

Lymphocyte vaccination. The activated, treated lymphocytes were thawed at $37^{\circ} \mathrm{C}$ and washed twice in HBSS. The cells were then resuspended in $0.9 \% \mathrm{NaCl}$ (saline) at a concentration of $1 \times 10^{8} / \mathrm{ml}$. Female NOD littermates, without evidence of glycosuria, were each randomly assigned to one of three treatment groups and injected with either the NOD vaccine (total treated $=30)$, the control vaccine $(n=30)$ or $0.9 \%$ saline $(n=26)$. Twelve weeks was selected as the prediabetic age since (i) only $6 \%$ of the mice are already diabetic at this stage and (ii) the incidence of diabetes rises sharply from the age of 14 weeks such that by 20 weeks approximately $80 \%$ of mice are diabetic. We have also shown that in our colony, $100 \%$ of mice at 10 weeks and $100 \%$ of mice at 14 weeks of age have insulitis (Phillips C.A. and Peakman M., unpublished observations). Cells were given in doses of $2 \times 10^{7}$ intraperitoneally at 12 weeks of age with further boosters at 13,14 and 15 weeks. Mice were followed to diabetes onset or 30 weeks of age. NOD mice were examined twice weekly for diabetes onset by testing for glycosuria using glucose test strips (Cambridge Laboratories, Newcastle Upon Tyne, UK) and a positive diagnosis of diabetes was taken to be greater than $8.3 \mathrm{mmol} / \mathrm{l}$ on two consecutive occasions 24-72 h apart.

In addition, a further group of 10 female NOD mice aged 12 weeks were injected with doses of $2 \times 10^{7}$ cells of NOD lymphocyte vaccine and received boosters of the same dose weekly until 30 weeks of age or diabetes onset, whichever was the sooner.

Histology. Pancreata were removed from a representative sample of 30-week-old non-diabetic mice from the NOD lymphocyte vaccinated group $(n=9)$, diabetic NOD mice from the control vaccinated group $(n=7)$ and diabetic mice from the saline injected group $(n=7)$ and stored under OCT embedding compound $(\mathrm{BDH})$ in liquid nitrogen. Unfixed $5 \mu \mathrm{m}$ cryostat sections were cut at different levels through the gland and stained with haematoxylin and eosin. Eight to 15 islets from each pancreas were examined under light microscopy by two observers blinded to the origin of the tissue. Islets were assessed for lymphocyte infiltration using five grades of severity and the mean score from each observer used: $0=$ no infiltration, 1 = polar-islet infiltration, 2 = peri-islet infiltration, $3=$ intra-islet infiltration and $4=$ extensive intra-islet infiltration [11].

Splenic lymphocyte subsets. Mononuclear cell suspensions were prepared from the spleens of a representative sample of non-diabetic mice from the NOD lymphocyte vaccinated 
group $(n=9)$, diabetic mice from the control vaccinated group $(n=10)$ and diabetic mice from the saline injected group $(n=9)$ and analysed by flow cytometry. Fifty microlitres of cell suspension at a concentration of $1 \times 10^{6} / \mathrm{ml}$ were incubated with fluorescein isothiocyanate (FITC) and phycoerythrin (PE) conjugated monoclonal antibodies (mAbs) for $30 \mathrm{~min}$ at $4^{\circ} \mathrm{C}$, washed in flow cytometry sheath fluid (Becton Dickinson, Oxford, UK) and analysed on a FACScan flow cytometer (Becton Dickinson). Five thousand gated events were recorded for each antibody combination. Combinations used were FITC conjugated anti-CD4 or anti-CD8 mAbs with PE conjugated anti-I-A mAbs to identify activated CD4 and CD8 cells (all mAbs supplied by Serotec, Oxford, UK). FITC and PEconjugated control mAbs directed against irrelevant targets were used to assess non-specific binding, which was subtracted from all counts.

Cytokine ELISA. Blood was drawn by cardiac puncture from NOD mice either at diabetes onset or at 30 weeks of age that had received either the NOD lymphocyte vaccine, the control lymphocyte vaccine or the saline carrier control. Blood was left to coagulate, spun at $1000 \mathrm{~g}$ for $10 \mathrm{~min}$ and serum removed for storage at $-80^{\circ} \mathrm{C}$ until analysis.

Levels of cytokines in the serum of NOD mice were analysed using a two-sited cytokine enzyme-linked immunosorbent assay (ELISA) (Pharmingen, San Diego, Calif., USA) and used according to the manufacturer's guidelines. Briefly, $100 \mu \mathrm{l} /$ well of monoclonal rat anti-mouse interleukin 4 (antiIL-4) or monoclonal rat anti-mouse interleukin-2 (anti-IL-2) diluted in $0.1 \mathrm{M}$ bicarbonate buffer ( $\mathrm{pH} 9.5$ ) to a concentration of $2 \mu \mathrm{g} / \mathrm{ml}$ were coated onto ELISA plates (Maxisorp Immunoplates, Nunc, Denmark) and incubated overnight at $4{ }^{\circ} \mathrm{C}$. Plates were washed 3 times in phosphate buffered saline (PBS, pH 7.4) supplemented with $0.05 \%$ Tween 20 (Sigma Chemical Co.) and non-specific binding sites blocked by incubation with $200 \mu \mathrm{l} /$ well dilution buffer (PBS/10\% fetal bovine serum albumin; Sigma Chemical Co.) for $2 \mathrm{~h}$ at room temperature. After washing, the standards and test sera diluted 1:2 were applied in duplicate and incubated overnight at $4{ }^{\circ} \mathrm{C}$. The plates were washed and $100 \mu \mathrm{l} /$ well of biotinylated monoclonal rat anti-mouse cytokine antibody added and incubated for $45 \mathrm{~min}$ at room temperature. The plates were then washed 6 times and $100 \mu \mathrm{l}$ of avidin peroxidase diluted 1/1000 in PBS/ $10 \%$ FCS was added to each well and incubated for $1 \mathrm{~h}$. The plate was again washed and the reaction was developed using $100 \mu \mathrm{l}$ substrate $(0.4 \mathrm{mg} / \mathrm{ml} O$-phenylenediamine in citrate phosphate buffer ( $\mathrm{pH} 5.0$ ) containing $4 \mu \mathrm{l} / \mathrm{ml}$ of $3 \%$ hydrogen peroxide), terminated with $100 \mu \mathrm{l}$ of $2 \mathrm{~mol} / \mathrm{l}$ sulphuric acid and optical density read in a Dynatech MR 700 automated plate reader at $490 \mathrm{~nm}$, blanking on a control well in which serum was substituted by PBS. A similar ELISA format was used to measure IFN- $\gamma$, but this cytokine was not detectable in any of the serum samples tested.

Immunohistochemistry. In the islet infiltrate, lymphocyte expression of CD4, CD8 and CD45RB, the production of the cytokines IFN- $\gamma$, IL-4 and the presence of macrophages was examined by immunohistochemistry. mAbs were prepared from rat hybridoma cell lines cultured in vitro (American Type Tissue Culture Collection; anti-murine CD4, clone Tib 207 GK1.5; anti-murine CD8, clone TIB 210 2.43; anti-murine macrophage, clone HB 198 F4/80; anti-murine IL-4, clone HB 188 IIBII; anti-murine IFN- $\gamma$, clone HB 170 R46A2) and purified from culture supernatants by protein $G$ affinity chromatography (Pharmacia, Uppsala, Sweden). Cryostat sections $(5 \mu \mathrm{m})$ of pancreas were fixed for $10 \mathrm{~min}$ in acetone, washed for $10 \mathrm{~min}$ in two changes of PBS and then incubated for
60 min with each mAbs diluted in PBS. The optimum dilution of each $\mathrm{mAb}$ was determined in preliminary experiments using sections from prediabetic mice that exhibited extensive insulitis. Sections were then washed and incubated for a further 60 min with a mouse absorbed polyclonal anti-rat FITC conjugated antibody (Dako, Oxford, UK). Background fluorescence, assessed by substituting PBS for the monoclonal antibodies, was minimal. The sections were then washed for 10 min in 2 changes of PBS.

The sections were analysed by UV microscopy and the lymphocyte infiltrate was assessed by two observers (C.G. and M.H., blinded to experimental details), using a semiquantitative scoring method, in which the approximate percentage of the islet infiltrate that stained positive with anti-cytokine antibodies was defined as $25,50,75$ or $100 \%$ and the degree of islet infiltration by cells stained with either antiCD4, anti-CD8, or anti-F4/80 mAb was scored from 0 to 4 as described above.

Statistical analysis. The effect of treatment on time to development of diabetes in the three test groups was examined by life table analysis and results compared using the log rank test. The Kruskal Wallis and Mann Whitney U tests were used to compare immunohistological scores, cytokine concentrations measured by ELISA and splenic lymphocyte subsets. $P$ values less than 0.05 were considered statistically significant.

\section{Results}

Effect of lymphocyte vaccination on diabetes onset. At 30 weeks, 13 of $30(43.3 \%)$ NOD mice remained nondiabetic in the group receiving NOD lymphocyte vaccine. By life table analysis, diabetes-free survival in this group was significantly prolonged compared to NOD mice receiving the NOD/B10-HTG vaccine $(5 / 26 ; 19.2 \% ; p<0.01)$ and the saline injected group $(2 / 30 ; 6.7 \% ; p<0.01)$ (Fig. 1$)$. There was no significant difference in diabetes-free survival between the two control groups.

We noted a marked reduction in the number of mice remaining non-diabetic in the NOD lymphocyte vaccinated group following the final vaccine booster at 15 weeks. Thus, the NOD lymphocyte vaccine prevented diabetes in a significant percentage of mice and also delayed its onset in a proportion for as long as the vaccine was being administered. For this reason, in a smaller number of mice, vaccine administration was prolonged.

Effect of prolonged vaccination. A further group of 10 female NOD mice received an injection of NOD lymphocyte vaccine at the prediabetic age of 12 weeks and received weekly boosters until 30 weeks of age. Only 2 of these mice developed diabetes and the remaining 8 remained non-diabetic at 30 weeks of age $(80 \%)$. Although this study group did not have a specific group of matched control mice, sham-treated weekly for the same period, comparison of diabetes prevention with that in control mice undergoing the shorter treatment regimens suggests that the 


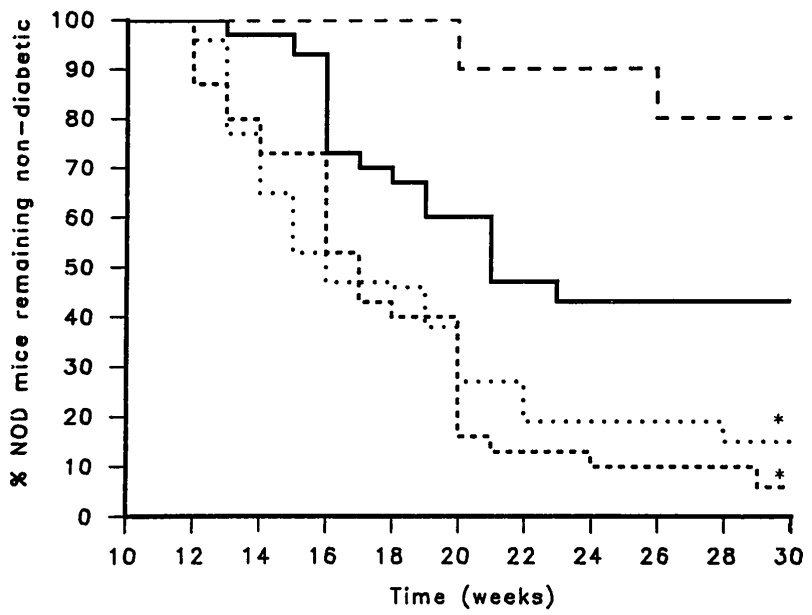

Fig. 1. Life table analysis of percentage of NOD mice remaining non-diabetic following weekly injection with either the NOD lymphocyte vaccine (-) the control (NOD/B10-derived) vaccine (--) or $0.9 \%$ saline $(\ldots \ldots)$ at the ages of 12 , 13,14 and 15 weeks. A further cohort of 10 mice received vaccine weekly between the ages of 12 and 30 weeks (-- ). The symbols refer to life table analysis of diabetes-free survival between the NOD lymphocyte vaccinated group and both of the control groups $(* p<0.01$ by log rank test)

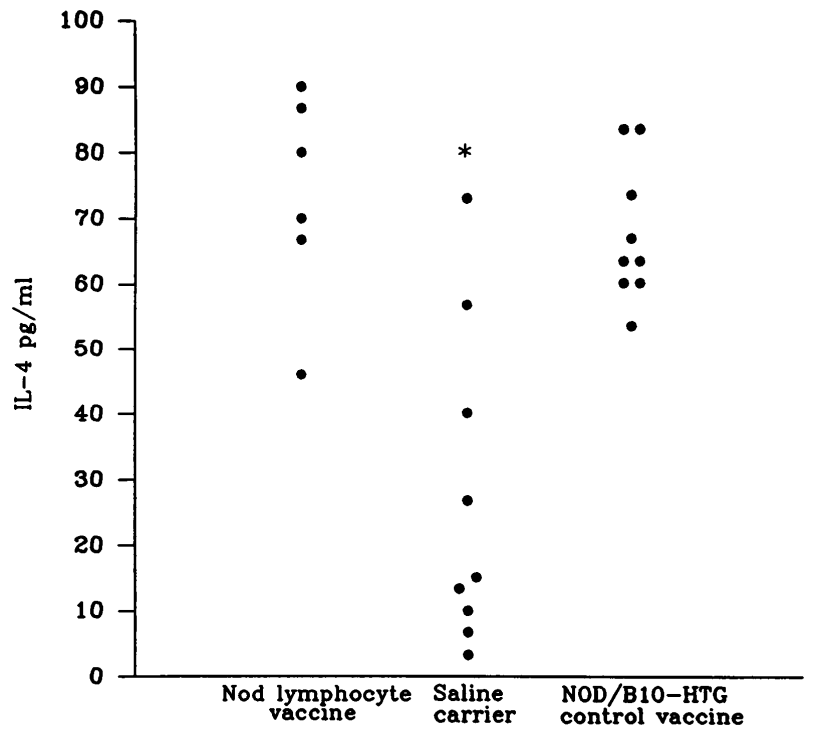

Fig. 2. Serum IL-4 concentrations in non-diabetic NOD mice that had received NOD lymphocyte vaccine and diabetic NOD mice that had received either control (NOD/B10 derived) vaccine or saline control. Serum levels of IL-4 are significantly elevated in mice receiving the NOD lymphocyte vaccine or the control NOD/B10 derived vaccine compared with saline treated controls $(p<0.005)$

protection afforded by lymphocyte vaccination can be increased with prolongation of the vaccination period $(p<0.01$ vs mice receiving NOD lymphocyte vaccine only between 12 and 15 weeks; $p<0.005$ vs mice receiving NOD/B10-HTG vaccine or saline carrier only between 12 and 15 weeks) (Fig. 1 ).
Histological examination of the pancreas. Analysis of pancreatic sections revealed considerable differences in the degree of infiltration of the islets of Langerhans in the different study groups. The insulitis score in the NOD lymphocyte vaccinated group (median 0.2 , range 0 to 3.5 ) was significantly lower than that of the control vaccinated group $(p<0.05)$ and the saline injected group $(p<0.05)$ (Table 1$)$. Of the 9 pancreata analysed from the NOD lymphocyte vaccinated group, 3 had a complete absence of infiltration in all of the islets studied, while a further 2 of the pancreata had a median score of 0 . In contrast, all pancreata from mice from the 2 control vaccinated groups had islets with at least some degree of infiltration and only 1 mouse in the control vaccinated group had a median score of 0 . There was no statistical difference in the insulitis score between the 2 control groups.

Serum cytokine levels. There was a significantly higher concentration of IL-4 in sera of mice remaining non-diabetic at 30 weeks after receiving 3 doses of NOD lymphocyte vaccine $(n=6$, median $=75 \mathrm{pg} / \mathrm{ml}$, range $=46-90 \mathrm{pg} / \mathrm{ml}$ ) compared with the saline injected control group $(n=8, \quad$ median $=20 \mathrm{pg} / \mathrm{ml}$, range $=3.3-73.3 \mathrm{pg} / \mathrm{ml} ; p<0.005)$ tested at diabetes onset. Diabetic mice receiving the control (NOD/ B10-HTG-derived) vaccine had serum levels of IL-4 comparable to the diabetes-free NOD lymphocyte vaccinated mice $(n=9$, median $68.3 \mathrm{pg} / \mathrm{ml}$, range 53.3-83.3 pg/ml; $p=$ NS) (Fig. 2).

Serum IL-2 levels in the NOD lymphocyte vaccine treated mice $(n=7$, median $60 \mathrm{pg} / \mathrm{ml}$, range $27.5-$ 106.5) were similar to both the saline treated mice $(n=8$, median 93.75, range $37.5-180 ; p=\mathrm{NS})$ and control vaccine treated group $(n=9$, median 112.5 , range $82.5-217.5 ; p=\mathrm{NS}$ ).

Cytokine expression and cellular subsets in the islet infiltrate. There was a significantly higher score for IFN- $\gamma$ staining in the diabetic mice that received the control (NOD/B10-HTG-derived) vaccine compared with mice that had received NOD lymphocyte vaccine and remained non-diabetic (Fig. 3 a, b, Table 2). The score for staining for IFN- $\gamma$ in saline-treated diabetic mice was similar to that in diabetic mice receiving the control vaccine, and higher than in non-diabetic mice receiving NOD vaccine, but not significantly so (Table 2 ). The percentage of infiltrating cells staining for IL-4 (Fig. $3 \mathrm{c}$ ) within the islets of the non-diabetic NOD lymphocyte vaccine mice was not statistically different when compared with diabetic mice from either of the control groups. However, since the severity of insulitis in the non-diabetic NOD vaccinated mice was much less, the total number of IL-4 positive cells is also lower by comparison.

CD8 + lymphocytes (Fig. $3 \mathrm{~d}$ ) were more prevalent in islets of diabetic saline treated mice $(n=7$, median 
Table 1. Insulitis scores in lymphocyte vaccinated NOD mice compared to controls

\begin{tabular}{lll}
\hline Treatment & $\begin{array}{l}\text { Median } \\
\text { score }\end{array}$ & Range \\
\hline NOD lymphocyte vaccine $(n=9)$ & 0.2 & $0-3.5$ \\
Control (NOD/B10-HTG) vaccine $(n=8)$ & $3.0^{\mathrm{a}}$ & $0.3-3.3$ \\
Saline control $(n=7)$ & $2.6^{\mathrm{a}}$ & $0.9-3.3$ \\
\hline
\end{tabular}

${ }^{\mathrm{a}} p<0.05$ vs NOD lymphocyte vaccinated group

Table 2. Percentage (median and range) of islet infiltrate staining with monoclonal antibodies to IL-4 and IFN- $\gamma$

\begin{tabular}{llc}
\hline Treatment & IL-4 & IFN- $\gamma$ \\
\hline NOD vaccine $(n=8)$ & $62.5(0-75)$ & $0(0-37.5)$ \\
Control vaccine $(n=7)$ & $62.5(50-75)$ & $50(25-75)^{\mathrm{a}}$ \\
Saline $(n=7)$ & $50(50-62.5)$ & $37.5(0-62.5)$ \\
\hline
\end{tabular}

${ }^{\mathrm{a}} p<0.01$ vs NOD lymphocyte vaccinated mice. IL-4 staining is similar in the 3 groups; IFN- $\gamma$ staining not significantly different in saline and NOD vaccine treated mice

Table 3. Insulitis scores of cellular infiltrate in the insulitis of mice receiving active and control vaccine and saline alone

\begin{tabular}{llll}
\hline Treatment & CD4 & CD8 & Macrophage \\
\hline NOD vaccine $(n=8)$ & $0(0-2)$ & $0(0-2)$ & $2(0-3)$ \\
Control vaccine $(n=7)$ & $2.5(1.5-3.5)^{\mathrm{b}}$ & $2(1.5-3)^{\mathrm{c}}$ & $2(0-2.5)$ \\
Saline $(n=7)$ & $2(0-3)$ & $2(0-3)^{\mathrm{a}}$ & $2(0-2)$ \\
\hline
\end{tabular}

Insulitis scores given in arbitrary units (see methods)

${ }^{\mathrm{a}} p<0.05,{ }^{\mathrm{b}} p<0.01,{ }^{\mathrm{c}} p<0.005$ vs NOD lymphocyte vaccinated group. CD4 staining was not significantly different in the saline and NOD vaccine treated mice

2 , range $0-3 ; p<0.05)$ and diabetic mice that received control (NOD/B10 derived) vaccine $(n=7$, median 2 , range $1.5-3.5 ; p<0.005)$ compared with the NOD lymphocyte vaccinated mice remaining non-diabetic $(n=8$, median 0 , range $0-2)$ (Table 3$)$. CD4 + lymphocytes (Fig. $3 \mathrm{e}$ ) were more frequent in mice receiving the control (NOD/B10-derived) vaccine $(n=7$, median 2.5, range 1.5-3.5) compared with non-diabetic mice receiving NOD lymphocyte vaccine $(n=8$, median 0 , range $0-2)$ (Table 3$)$. In saline-treated diabetic mice, infiltrating CD4 + lymphocyte scores $(n=7$, median 2 , range $0-3)$ were similar to those in control vaccine-treated mice, and higher than in NOD lymphocyte vaccinated mice, but not significantly so (Table 3 ). Scores for the assessment of the extent of macrophage infiltration were similar in the 3 study groups (Fig. 3 f, Table 3 ).

Splenic lymphocyte subsets. The percentage of activated CD4 + and CD8 + lymphocytes in the spleen detected by flow cytometry was similar in the three study groups.

\section{Discussion}

In this study diabetes development was retarded or prevented in prediabetic NOD mice following treatment with NOD lymphocyte vaccine at 12 weeks of age. Perhaps the most notable effect of the vaccine accompanying prevention of diabetes development was in the striking decrease of infiltrating cells from the islets. NOD mice protected by treatment with the NOD lymphocyte vaccine and remaining non-diabetic at 30 weeks had a significantly and markedly reduced degree of insulitic infiltration, such that in the majority of pancreata examined in this group, islets were completely free of infiltration.

We have previously shown that lymphocyte vaccine administered at an early age (6 weeks) is effective in reducing the incidence of diabetes in our NOD mouse colony by approximately $50 \%$ [8]. In mice vaccinated at 6 weeks of age, insulitis is barely detectable [12] and, typically, therapies initiated at this stage have a much greater chance of successfully preventing diabetes. Such early studies, therefore, are useful for indicating whether a therapy has any potential for human IDDM, but not for planning the timing of clinical intervention, since there is not an equivalent early stage of the disease in man that can be readily identified. In the present study, we aimed to examine the potential use of lymphocyte vaccination in the prediabetic period, identifiable in the first degree relatives of patients with IDDM through screening for islet cell and other autoantibodies [9]. The selection of an equivalent population of prediabetic NOD mice was made difficult by the lack of comparable serological markers predictive of diabetes. We selected 12 weeks of age as the immediately prediabetic stage since insulitis, which begins at approximately 4 weeks of age, is well established in the majority of mice in our colony by 12 weeks and could be expected to progress to complete beta-cell destruction by week 16 in $60-80 \%$ of mice. At 12 weeks $94 \%$ of mice are non-diabetic, but by 18 weeks diabetes has occurred in $80 \%$. The aim of preventing diabetes in NOD mice at the age of 12 weeks, therefore, represents a challenging but clinically relevant test of treatment efficacy. Few other intervention studies in this model have attempted treatment in NOD mice beyond 6 weeks. Indeed, the current use of insulin in diabetes prevention trials in high-risk first degree relatives is based upon studies of NOD mice treated within the first 5 weeks of life [13]. The success of lymphocyte vaccination in prediabetic NOD mice, all of whom would be expected to have had significant insulitis at the time the therapy was initiated, suggests that it may be an effective therapy in the prevention of disease progression in clinical prediabetes.

Despite numerous studies the precise mechanism by which lymphocyte vaccination is effective in animal models of autoimmune disease is not clear. It 

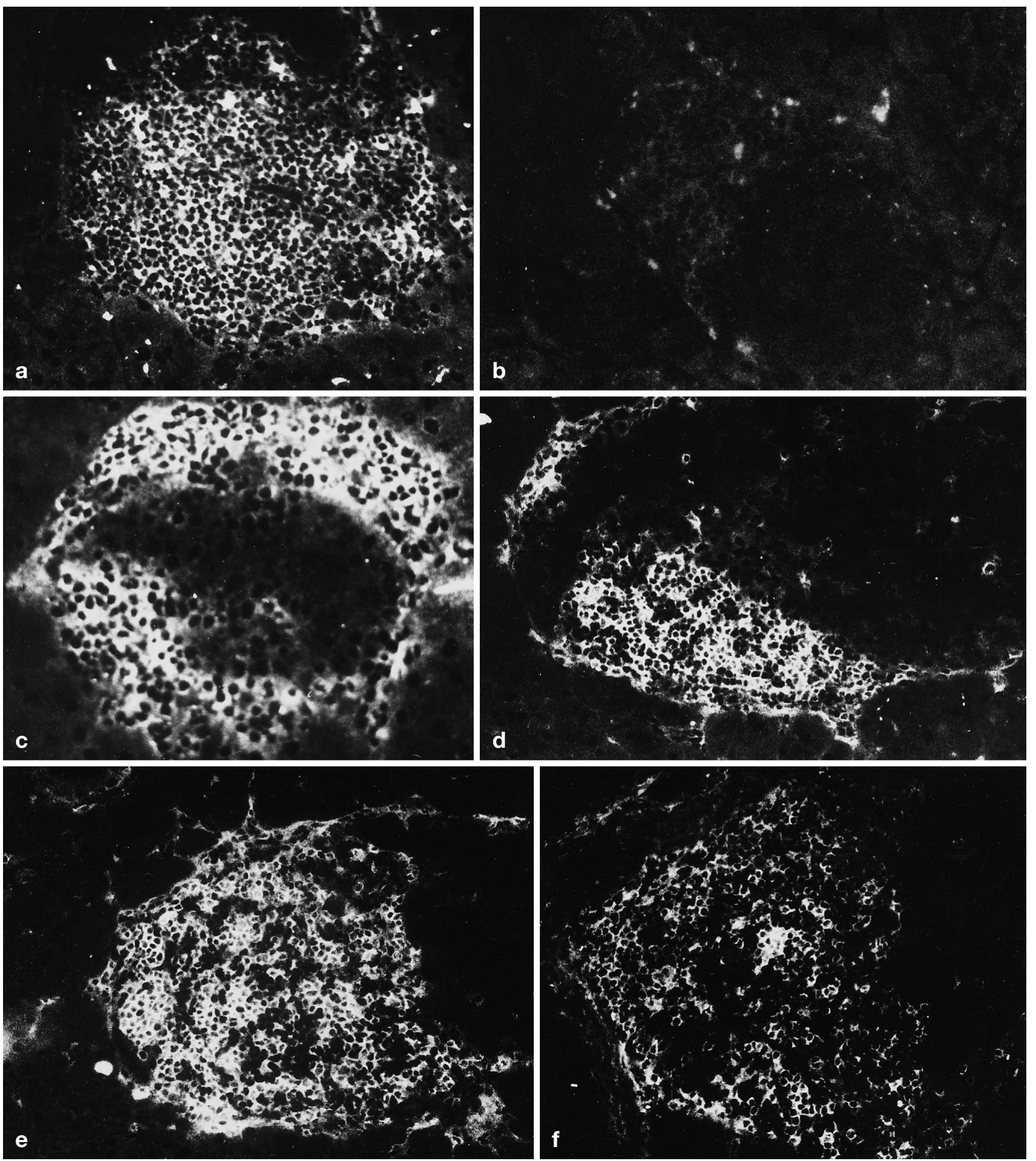

Fig.3a-f. Immunofluoresence staining of islets of Langerhans from female diabetic NOD mice using $\mathrm{mAb}$ specific for (a) IFN- $\gamma$ (c) IL-4 (d) CD8 (e) CD4 (f) F4/80 (macrophage). (b) shows the markedly reduced IFN- $\gamma$ staining seen in a non-diabetic mouse which received the NOD lymphocyte vaccine has been proposed that regulation of autoimmune disease is controlled by interactions between a network of suppressor and cytotoxic cells [14], and there is considerable evidence for both of these populations existing in NOD mice [15-17]. It is further suggested that raising an immune response to a vaccine composed of autoreactive $\mathrm{T}$ cells activates an anti-idiotypic set of regulatory lymphocytes capable of suppressing or eliminating cells infiltrating the target organ, thus allowing recovery $[3,6,18]$. Studies in the 
experimental animal model of multiple sclerosis and early clinical trials in multiple sclerosis patients have provided evidence that vaccination with attenuated autoreactive $\mathrm{T}$ cells does indeed stimulate such an anti-idiotypic response. It has also been demonstrated that the presence of activation determinants on the vaccine cells is critical to prevention of disease onset, generating a so-called anti-ergotypic response [19]. In the present study we demonstrate that specific characteristics of NOD lymphocytes are also a prerequisite for a successful lymphocyte vaccine in this model, since the control vaccine, composed of activated lymphocytes of the NOD/B10-HTG strain, did not impart any protection.

We examined the possibility that an alteration in activated splenic lymphocyte populations accompanied a reduction in insulitis. Since our results suggested that this is not a feature of the therapy, we also examined effects of lymphocyte vaccination on cytokine secretion by the cells in the insulitis and in serum. Diabetic mice receiving either the control vaccine or saline demonstrated high levels of IFN- $\gamma$ staining of infiltrating cells, consistent with previous suggestions that $\beta$-cell destruction is predominantly mediated by $\mathrm{T}_{\mathrm{H}} 1$ cells [20-23], whereas IFN- $\gamma$ staining was entirely absent in the majority of non-diabetic mice treated with active NOD vaccine. Staining with IL-4 occurred to a similar degree in mice treated with active and control vaccines. Serum levels of IL4 were significantly higher in the non-diabetic NOD vaccine-treated and diabetic control-vaccine treated mice compared with the diabetic saline treated control group. Thus, it would appear that lymphocyte vaccines may have a non-specific effect in inducing IL-4 production, irrespective of their effects on the progression of diabetes in this model.

In both the present and our previous study [8], the life table indicated that cessation of administration of the vaccine was associated with immediate onset of diabetes in a small number of mice treated with the active vaccine. This suggests that in some mice, possibly those with the most advanced insulitis at the time the vaccine was commenced, the vaccine was only active for the duration of treatment. To ascertain whether prolonged administration of the NOD vaccine gave a higher level of protection, treatment was maintained weekly from 12 to 30 weeks in 10 mice, with $80 \%$ of mice remaining non-diabetic to this age. This indicates that maintenance of the protective immune response, whether anti-idiotypic or $\mathrm{T}_{\mathrm{H}} 2$ driven, requires re-stimulation with immunogenic vaccine cells, and this may have implications for the clinical use of this therapy.

Lymphocyte vaccination has already undergone clinical trials in several diseases, including multiple sclerosis and rheumatoid arthritis, and the therapy has been shown to be safe while achieving some success in modifying disease activity [5-7]. Our present study supports the view that such a safe therapy could be appropriate for trials in individuals at high risk of developing IDDM.

Acknowledgements. This work was funded by The Sir Jules Thorn Charitable Trust, which supported C.L.G. M.J.H. is supported by the South Thames Regional Health Authority. M.P. is a Senior Clinical Research Fellow of the British Diabetic Association.

\section{References}

1. Wicker LS, Miller BJ, Mullen Y (1986) Transfer of autoimmune diabetes mellitus with splenocytes from nonobese diabetic (NOD) mice. Diabetes 35: 855-856

2. Ben-Nun A, Wekerle H, Cohen IR (1981) Vaccination against autoimmune encephalomyelitis with $\mathrm{T}$ lymphocyte line cells reactive against myelin basic protein. Nature 292: 60-61

3. Lider O, Karin N, Shinitzky M, Cohen IR (1987) Therepeutic vaccination against adjuvant arthritis using autoimmune T cells treated with hydrostatic pressure. Proc Natl Acad Sci USA 84: 4577-4580

4. Maron R, Zerubavel R, Friedman A, Cohen IR (1983) T lymphocyte line specific for thyroglobulin produces or vaccinates against autoimmune thyroiditis in mice. J Immunol 131: 2316-2322

5. Hafler DA, Cohen IR, Benjamin DS, Weiner HL (1992) T cell vaccination in multiple sclerosis: a preliminary report. Clin Immunol Immunopathol 62: 307-311

6. Zhang J, Medaer R, Stinissen P, Hafler D, Raus J (1993) MHC-restricted depletion of human myelin basic proteinreactive $\mathrm{T}$ cells by $\mathrm{T}$ cell vaccination. Science 261: $1451-$ 1454

7. Van-Laar JM, Miltenburg AM, Verdonk MJ et al. (1993) Effects of inoculation with attenuated autologous T cells in patients with rheumatoid arthritis. J Autoimmun 6: 159167

8. Smerdon RA, Peakman M, Hussain MJ, Vergani D (1993) Lymphocyte vaccination prevents spontaneous diabetes in the non-obese diabetic mouse. Immunology 80: 498-501

9. Bingley PJ, Christie MR, Bonifacio E et al. (1994) Combined analysis of autoantibodies improves prediction of IDDM in islet cell antibody-positive relatives. Diabetes 43: 1304-1310

10. Wicker LS, Miller BJ, Coker LZ et al. (1987) Genetic control of diabetes in the nonobese diabetic (NOD) mouse. $\mathrm{J}$ Exp Med 165: 1639-1654

11. Peterson JD, Pike B, McDuffie M, Haskins K (1994) Isletspecific $\mathrm{T}$ cell clones transfer diabetes to nonobese diabetic (NOD) F1 mice. J Immunol 153: 2800-2806

12. Signore A, Pozzilli P, Gale EAM, Andreani D, Beverley PCL (1989) The natural history of lymphocyte subsets infiltrating the pancreas of NOD mice. Diabetologia 32: 282289

13. Atkinson MA, Maclaren NK, Luchetta R (1990) Insulitis and diabetes in NOD mice reduced by prophylactic insulin therapy. Diabetes 39: 933-937

14. Cohen IR, Atlan H (1989) Network regulation of autoimmunity: an automation model. J Autoimmun 2: 613-625

15. Reich EP, Scaringe D, Yagi J, Sherwin RS, Janeway CA Jr (1989) Prevention of diabetes in NOD mice by injection of autoreactive T-lymphocytes. Diabetes 38: 1647-1651

16. Chosich N, Harrison LC (1993) Suppression of diabetes mellitus in the non-obese diabetic (NOD) mouse by an 
autoreactive (anti-I-Ag7) islet-derived CD4 + T-cell line. Diabetologia 36: 716-721

17. Serreze DV, Leiter EH (1988) Defective activation of T suppressor cell function in nonobese diabetic mice. Potential relation to cytokine deficiencies. J Immunol 140: 38013807

18. Lider O, Reshef T, Beraud E, Ben-Nun A, Cohen IR (1988) Anti-idiotypic network induced by $\mathrm{T}$ cell vaccination against experimental autoimmune encephalomyelitis. Science 239: 181-183

19. Lohse AW, Mor F, Karin N, Cohen IR (1989) Control of experimental autoimmune encephalomyelitis by T cells responding to activated T cells. Science 244: 820-822

20. Kaufman DL, Clare-Salzler M, Tian J et al. (1993) Spontaneous loss of T-cell tolerance to glutamic acid decarboxylase in murine insulin-dependent diabetes. $\mathrm{Na}$ ture 366: 69-72

21. Trembleau S, Penna G, Bosi E, Mortara A, Gately MK, Adorini L (1995) Interleukin 12 administration induces T helper type 1 cellsand accelerates autoimmune diabetes in NOD mice. J Exp Med 181: 817-821

22. Healey D, Ozegbe P, Arden S, Chandler P, Hutton J, Cooke A (1995) In vivo activity and in vitro specificity of CD4 + Th1 and Th2 cells derived from the spleens of diabetic NOD mice. J Clin Invest 95: 2979-2985

23. Pennline KJ, Roque-Gaffney E, Monahan M (1994) Recombinant IL-10 prevents the onset of diabetes in the nonobese diabetic mouse. Clin Immunol Immunopathol 71: 169-175 